\title{
Improved Functional Activity of Bone Marrow Derived Circulating Progenitor Cells After Intra Coronary Freshly Isolated Bone Marrow Cells Transplantation in Patients with Ischemic Heart Disease
}

\author{
R. Goekmen Turan • I. Bozdag-T • J. Ortak • S. Kische $\cdot$ I. Akin $\cdot$ H. Schneider • \\ C. H. Turan - T. C. Rehders - M. Rauchhaus • T. Kleinfeldt • C. Belu • M. Brehm • \\ S. Yokus $\cdot$ S. Steiner $\cdot$ K. Sahin • C. A. Nienaber $\cdot$ H. Ince
}

Published online: 29 December 2010

(C) The Author(s) 2010. This article is published with open access at Springerlink.com

\begin{abstract}
Objectives There is growing evidence that intracoronary autologous bone marrow cells transplantation (BMCs-Tx) in patients with chronic myocardial infarction beneficially affects postinfarction remodelling. In this randomized controlled study we analyzed the influence of intracoronary autologous freshly isolated bone marrow cells transplantation by use of point of care system on cardiac function and on the functional activity of bone marrow derived circulating progenitor cells (BM-CPCs) in patients with ischemic heart disease (IHD).

Methods 56 patients with IHD were randomized to either received freshly isolated BMC-Tx or a control group that did not receive cell therapy. The functional activity of BM-CPCs in peripheral blood (PB) was measured by migration assay and colony forming unit assay pre- and 3 ,
\end{abstract}

R. G. Turan $(\bowtie) \cdot$ I. Bozdag-T $\cdot$ J. Ortak $\cdot$ S. Kische $\cdot$ I. Akin $\cdot$

H. Schneider - C. H. Turan • T. C. Rehders • M. Rauchhaus •

T. Kleinfeldt $\cdot$ C. Belu $\cdot$ C. A. Nienaber $\cdot$ H. Ince

Department of Internal Medicine, Division of Cardiology,

Rostock-University,

Ernst Hydemann Str 618055

Rostock, Germany

e-mail: dr_g_turan@hotmail.com

\section{Brehm $\cdot$ S. Yokus $\cdot$ S. Steiner}

Laboratory of Stem Cell Transplantation and Molecular

Cardiology, Department of Internal Medicine,

Division of Cardiology, Pneumology and Angiology,

Heinrich-Heine-University,

Duesseldorf, Germany

K. Sahin

Institute for Clinical Research and Statistics,

Cologne, Germany
6 as well as 12 months after procedure. Global ejection fraction $(\mathrm{EF})$ and infarct size area were determined by left ventriculography.

Results Intracoronary transplantation of autologous freshly isolated BMCs led to a significant reduction of infarct size and an increase of global EF as well as infarct wall movement velocity after 3 and 12 months follow-up compared to control group. The colony-forming capacity of BM-CPCs significantly increased 3, 6 and 12 months after cell therapy compared to pre BMCs-Tx and control group (CFU-E: $p<0.001$, CFU-GM: $p<0.001$ ). Likewise, we found significant increase of migratory response to stromal cell-derived factor 1 (SDF-1) and vascular endothelial growth factor (VEGF) after cell therapy compared to pre BMCs-Tx (SDF-1: $p<0.001$, VEGF: $p<0.001)$ and to control (SDF-1: $p<0.001$, VEGF: $p<0.001$ ). There was no significant difference of migratory- and colony forming capacity between pre- and 3, 6, 12 months after coronary angiography in control group without cell therapy.

Conclusions Intracoronary transplantation of autologous freshly isolated BMCs by use of point of care system may lead to improvement of BM-CPCs functional activity in peripheral blood, which might increase the regenerative potency in patients with IHD.

Keywords Migration capacity - Colony forming capacity · Ischemic heart disease $\cdot$ Bone marrow cell transplantation

\section{Introduction}

Circulating progenitor cells (CPCs) are primitive bone marrow cells (BMCs) that have the capacity to proliferate, 
migrate, and differentiate into various mature cell types [13]. Furthermore, these cells circulate in the peripheral blood (PB), and implicate in neoangiogenesis after tissue ischemia $[4,5]$. Cell therapy is a promising novel option to improve vascularization or cardiac regeneration [6]. In animal models, bone marrow-derived stem/progenitor cell infusion improves cardiac function and neovascularization after myocardial infarction [7-10]. Additionally, clinical trials indicate a benefical effect of intra coronary infusion of BMCs or circulating progenitor cells (CPCs) on myocardial function in patients with acute myocardial infarction (AMI) [11-15]. Moreover, it has been suggested that cardiovascular risk factors (CVRFs) are associated with reduction of functional activity of BM-CPCs in patients with coronary artery disease as well as in healthy men $[16,17]$. It is unknown whether freshly isolated BMCs transplantation and the functional activity of BM-CPCs in $\mathrm{PB}$ have beneficially affects postinfarction remodelling. In this prospective randomized control trial, we analyzed the influence of intracoronary freshly isolated cell therapy by use of point of care system on cardiac function and on the functional activity of the bone marrow derived circulating progenitor cells (BM-CPCs) in patients with ischemic heart disease (IHD).

\section{Methods}

\section{Patients}

In a prospective randomized controlled trial, patients between 18 and 80 years of age were eligible for inclusion in this study if they had had a documented MI at least 3 months and had a clear-cut demarcated region of left ventricular dysfunction with an open infarct-related coronary artery at the time of stem cell therapy. Exclusion criteria were the presence of acutely decompensated heart failure with a New York Heart Association (NYHA) class of IV, infectious or inflammatory disease, active bleeding, surgery or trauma within 2 months, renal or liver dysfunction, thrombocytopenia, or anemia, alcohol or drug dependency, a history of other severe chronic diseases or cancer, or unwillingness to participate. The local ethics committee approved the study protocol. All IHD patients were discharged with standard medication consisting of acetylsalicylic acid and/or clopidogrel, an ACE inhibitor, a ß-blocker and a statin.

\section{Study Protocol}

In this study 56 patients with IHD were randomly allocated in a 2:1 ratio to either receive intracoronary autologous freshly isolated BMCs-Tx, or a control group no stem cell therapy. All patients suffered a transmural myocardial infarction (MI) $28 \pm 14$ months before stem cell therapy (STX). All of these patients were treated acutely by PTCA plus stent implantation. We performed in all patients of both groups $8 \pm 2$ months before cell transplantation a coronary angiography as well as a left ventriculography and presented with open infarct-related coronary arteries. These patients were randomized to either receive intracoronary autologous freshly isolated bone marrow cell (BMC) transplantation, or to a control group without stem cell therapy. Patients included in the stem cell group underwent a bone marrow puncture and BM aspiration on day 1 after admission. BMCs were separated. Subsequently, after coronary angiography and left ventriculography, the BMCs were freshly transplanted intracoronary. Patients in the control group received only coronary angiography and left ventriculography without any cell based therapy. In both groups all patients with angiographically relevant coronary restenosis (5 patients from the BMCs-Tx and 2 patients from the control group) were treated by PTCA plus stent implantation and have been excluded from the study. We examined all patients in both groups after 3 and 12 months by coronary angiography and left ventriculography. The primary end point of the study was the change in global EF as well as the size of infarcted area measured by left ventriculography after 3, and 12 months. Secondary end points were the functional activity of BM-CPCs immediately pre and 3,6 as well as 12 months after procedure. Functional status was assessed by NYHA classification and brain natriuretic peptide (BNP: normal value $<100 \mathrm{pg} / \mathrm{ml}$ ) level in PB in both groups (Fig. 1).

Figures 2 and 3

\section{Preparation and Administrations of BMC}

A total of approximately $120 \mathrm{mls}$ of bone marrow was aspirated from the iliac crest after local anesthesia and mononuclear cells were isolated and identified including CD $34^{+}$and $\mathrm{CD} 133^{+}$. The bone marrow cell concentrate suspension was isolated by use of point of care system (Harvest BMAC System, Harvest Technologies GmbH, Munich, Germany) according to the manufactures instructions for use to produce $20 \mathrm{mls}$ of concentrated cells. The concentrate consisted of a heterogeneous cell population including hematopoietic, mesenchymal, other progenitor cells as well as granulocytes and platelets.

After undergoing arterial puncture, all patients received 7500-10000 Units of heparin. Cell transplantation was performed via the intracoronary administration route [12] using four fractional infusions parallel to balloon inflation over 2-4 min of $5 \mathrm{ml}$ of cell suspension. All cells were infused directly into the infarcted zone through the infarct related artery via an angioplasty balloon catheter, which 
Fig. 1 Enrollment and followup analysis of trial

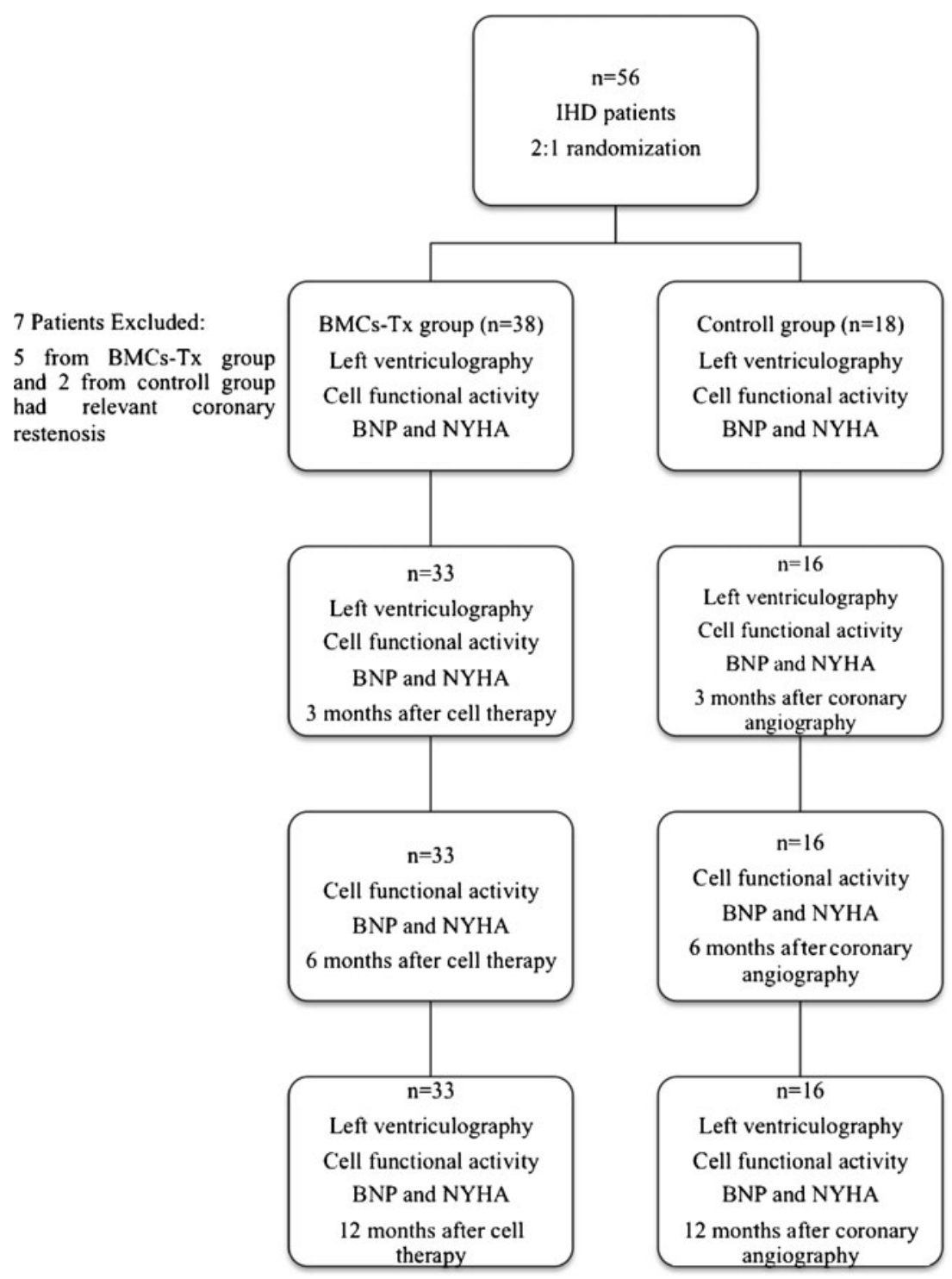

was inflated at a low pressure (4 atm) and was located within the previously stented coronary segments. This prevented back flow of cells and produced stop flow beyond the site of balloon inflation to facilitate highpressure infiltration of cells into the infarcted zone with prolonged contact time for cellular migration. Three months after catheter-guided cell transplantation, all functional tests were repeated, including coronary angiography and left ventriculography. There were no procedural or cell-induced complications and there were no side effects in any patients.

\section{Coronary Angiography and Left Ventriculography}

Patients in both groups underwent left heart catheterization, left ventriculography and coronary angiography. Cardiac function and infarct size were determined by left ventriculography. Cardiac function was evaluated by global EF and by auxotonic myocardial contractility index, evaluated by the wall movement velocity of the infarcted area. Global EF was measured with Quantcor software (Siemens, Erlangen/ Germany). To quantify the size of infarct area we used the centreline method according to Sheehan [18] by plotting five axes perpendicular to the long axis of the heart in the main akinetic or dyskinetic segment of ventricular wall. Systolic and diastolic lengths were then measured by two independent observers, and the mean difference was divided by systolic duration in seconds. The follow-up was 3 and 12 months after the treatment. All hemodynamic investigations were obtained by two independent observers.

Isolation and Cultivation of BM-CPCs

$20 \mathrm{ml}$ peripheral venous blood was taken using a BD Vacutainer $\mathrm{CPT}^{\mathrm{TM}}$ from each patient. BM-CPCs were 

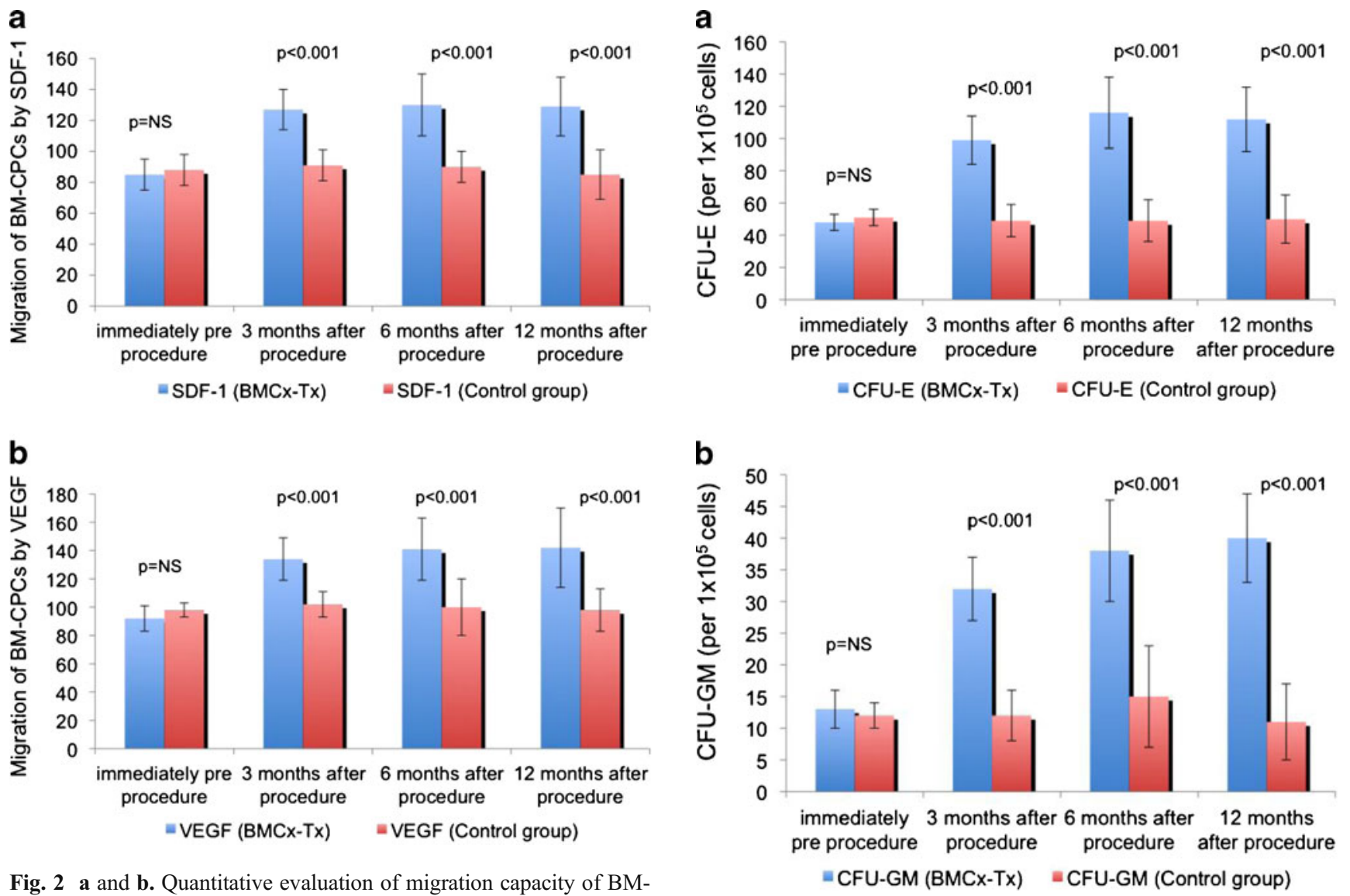

Fig. 2 a and b. Quantitative evaluation of migration capacity of BMCPCs. There was a significant increase of migratory response to SDF1 and VEGF 3, 6 and 12 months after intracoronary freshly isolated BMCs-Tx compared to baseline and to control group, whereas there was no significant difference between immediately pre and 3, 6, 12 months after coronary angiography in the control group. Bone marrow cell transplantation (BMCs-Tx), stromal cell-derived factor 1 (SDF-1) and vascular endothelial growth factor (VEGF)

isolated by density gradient centrifugation. After 2 washing steps, cells were resuspended in $1 \mathrm{ml}$ EBM2-medium (Cell system). The number of isolated BM-CPCs were determined in a Neubauer chamber $[17,19]$.

\section{Assessment of Migration Assay}

A total of $1 \times 10^{6} \mathrm{BM}$-CPCs were resuspended in $250 \mu \mathrm{l} \mathrm{X}$ Vivo and placed in the top compartment of a Boyden Chamber. This chamber was placed in a 24 -well culture dish contained either only EBM-2 medium or $100 \mathrm{ng} / \mathrm{ml}$ stromal cell derived factor-1 (SDF-1) or $100 \mathrm{ng} / \mathrm{ml}$ vascular endothelial growth factor (VEGF) in EBM2-medium. After $24 \mathrm{~h}$ of incubation at $37^{\circ} \mathrm{C}$ transmigrated cells were counted by 2 independent investigators [17, 19]. Quantitative evaluation of migrated cells to SDF-1 and VEGF were analyzed in comparison to cells without chemokine in blood samples of both groups. Values are expressed as $\%$ of migrated cells without chemokine.

Fig. 3 a and b. Colony forming unit is expressed as number of colonies per $1 \times 10^{5}$ seeded BM-CPCs. Values are mean \pm SEM. Colony forming capacity of BM-CPCs increased significantly 3,6 and 12 months after cell therapy as compared to baseline and to control group. No significant difference was observed in the colony forming capacity between baseline and 3, 6, 12 months after coronary angiography in patients without cell therapy. Bone marrow derived circulating progenitor cell (BM-CPCs)

\section{Assessment of Colony Forming Unit Assay}

$1 \times 10^{5}$ in BM-CPCs per $\mathrm{ml}$ were seeded in Methocult GF H4435 (Stemcell Technologies). Culture dishes were seeded with $1 \mathrm{ml}$ cell suspension and then incubated at $37^{\circ} \mathrm{C}$. Colony-forming unit erythroid (CFU-E) and CFUgranulocyte/macrophage (CFU-GM) were studied under phase-contrast microscopy and were counted after 14 days of incubation by 2 independent investigators [19].

\section{Safety Parameters}

To assess any inflammatory response and myocardial reaction after cell therapy, white blood cell count, the serum levels of C-reactive protein (CRP) and of creatine kinase $(\mathrm{CK})$ were determined immediately before and after treatment. Additional analysis was done directly after transplantation and 3, 6, 12 months later: BNP level in 
PB, ECG at rest, 24-h Holter ECG and echocardiography. Procedural complications were defined as any ventricular arrhythmia, visible thrombus formation, distal embolization, or injury of the coronary artery associated with the cell infusion catheterization procedure.

\section{Statistical Analysis}

Quantitative data are presented with mean \pm SD and qualitative data are tabulated using absolute frequencies and/or percentages. Differences between therapy groups for qualitative variables were tested using Fisher's-Exact-Test due to small number of patients in therapy groups. Within differences of quantitative variables in each therapy group are compared using the Wilcoxon-Test for depending samples, and differences between therapy groups of quantitative variables are compared with the WilcoxonTest for independent samples. Both of those nonparametric Wilcoxon-Tests are preferred due to the more likely expected non-normal distribution of the data. For all statistical tests, a result will be seen as statistically significant, if the corresponding two-sided $p$-value is smaller or equal to 0.05 . If the mean and the median did not differ markedly for a variable, the graphical presentation of the data was be done using the mean and SD of this variable. Statistical analysis was performed with SPSS for Windows (Version 15.0)

\section{Results}

Baseline Characteristics of The Patients

We randomized 56 patients with IHD (2:1) in the study. 38 patients in the intervention group received freshly isolated BMCs-Tx, whereas 18 patients in second group received no intra coronary BMCs-Tx and served as a control. There were no significant difference between the baseline characteristics and demographics of patients between both groups (Table 1).

\section{Effect of BMCs Transplantation}

Left Ventricular Function, Infarct Size and Infarct Wall Movement Velocity

Global EF, LVEDV, LVESV, SVI, infarct size and the wall movement velocity were measured by left ventriculography in the first group immediately before and 3,12 months after BMCs-Tx as well as in the second group without BMCs-Tx pre- and 3, 12 months after cardiac catheterization. There were no significant baseline differences in global EF, infarct size and infarct wall movement velocity between the two groups (Tables 2 and 3 and Fig. 4a, b and c). 3 and 12 months after cell therapy, we observed a significant increase of global EF and infarct wall movement velocity compared to baseline. Furthermore, we found significant decrease of infarct size after 3 and 12 months compared to baseline (Table 2). Moreover, global EF and wall movement velocity of the infracted area significantly increased 3 and 12 months after cell therapy compared to control group. Infarct size significantly decreased 3 and 12 months after BMCs-Tx as compared to control group without cell therapy (Fig. 4a, b and c). Moreover, we found a significant increase of SVI and decrease of LVESV whereas no significant change was observed in LVEDV 3 and 12 months after cell therapy (Table 2). In the control group there were no significant changes in global EF, LVEDV, LVESV, SVI, infarct size and the wall movement velocity of the infarcted area 3 and 12 months after coronary angiography (Table 3 ).

\section{Functional Status and Clinical Safety Parameters}

To determine the functional status we assessed NYHA classification in both groups by two independent and blinded physicians. There were no significant differences of at baseline NYHA classification and BNP levels between both groups. We observed significant a improvement in NYHA classification 3, 6 and 12 months after intracoronary cell therapy, whereas there was no significant difference in control group 3, 6 and 12 months after coronary angiography. Furthermore, we found a significant decrease of BNP level in PB three months after BMCs-Tx with no significant difference observed in control group 3, 6 and 12 months after coronary angiography (Tables 2 and 3 ). NYHA classification and BNP levels significantly decreased 3, 6 and 12 months after cell therapy compared to control group (Fig. 5a and b).

ECG at rest, on exercise and 24-h Holter ECG revealed no rhythm disturbances. There was no inflammatory response or myocardial infarction (white blood cell count, CRP, CK) after cell therapy. No immediate periprocedure as well as post procedure adverse complications and no new electrocardiographic changes or significant elevations in CK or troponin as well as no inflammatory response were observed in patients with BMC-Tx

\section{Functional Activity of BM-CPCs After Cell Therapy}

The functional capacities of BM-CPCs were measured by migratory- and colony forming activity in both groups immediately pre- and 3, 6, 12 months after index procedure. The migratory response to SDF-1 and VEGF increased significantly 3, 6 and 12 months after intra coronary BMCsTx compared to baseline and to control group. In contrast, 
Table 1 Baseline clinical characteristics of patients with ischemic heart disease with bone marrow cells transplantation and control group without transplantation

\begin{tabular}{|c|c|c|c|}
\hline & IHD with BMCs-Tx $(n=38)$ & IHD without BMCs-Tx $(n=18)$ & $\mathrm{P}$ \\
\hline Age & $62 \pm 10$ & $60 \pm 9$ & NS \\
\hline $\mathrm{m} / \mathrm{f}$ & $20 / 18$ & $10 / 8$ & NS \\
\hline \multicolumn{4}{|l|}{ Cardiovascular Risk Factors (\%) } \\
\hline Hypertension & 60 & 65 & NS \\
\hline Hyperlipidemia & 60 & 65 & NS \\
\hline Smoking & 80 & 80 & NS \\
\hline Diabetes & 20 & 25 & NS \\
\hline Positive family history of CAD & 20 & 10 & NS \\
\hline Transmural myocardial infarction, months before $\mathrm{Tx}$ & $28 \pm 13$ & $27 \pm 14$ & NS \\
\hline No. of diseased vessels & $1.9 \pm 0.5$ & $2.0 \pm 0.6$ & NS \\
\hline Infarct-related vessel (LAD/LCX/RCA) & $22 / 8 / 8$ & $10 / 5 / 3$ & NS \\
\hline PTCA/Stent at the time of AMI & $38 / 38$ & $18 / 18$ & NS \\
\hline \multicolumn{4}{|l|}{ Medication (\%) } \\
\hline Aspirin & 100 & 100 & NS \\
\hline Clopidogrel & 100 & 100 & NS \\
\hline ACE inhibitor or AT II blocker & 100 & 100 & NS \\
\hline Beta-blocker & 100 & 100 & NS \\
\hline Aldosterone Antagonist & 20 & 20 & NS \\
\hline Statin & 100 & 100 & NS \\
\hline \multicolumn{4}{|l|}{ Laboratory parameters } \\
\hline $\mathrm{CK} \mathrm{U/L}$ & $2018 \pm 560$ & $2000 \pm 740$ & NS \\
\hline
\end{tabular}

$I H D$ Ischemic heart disease, BMCs-Tx Bone marrow cells transplantation, $C A D$ Coronary artery disease, PTCA Percutaneous transluminal coronary angioplasty, $C K$ Creatine kinase, $L A D$ Left anterior descending coronary artery, $L C X$ Left circumflex artery, $R C A$ Right coronary artery, $N S$ None significant. Quantitative data are presented with mean $\pm \mathrm{SD}$

Table 2 Cardiac function, clinical function status parameters and functional activity of BM-CPCs at baseline and 3, 6 as well as 12 months after freshly isolated BMCs-Tx in the firstgroup

\begin{tabular}{|c|c|c|c|c|}
\hline & $\begin{array}{l}\text { Immediately pre } \\
\text { BMCs-Tx }\end{array}$ & $\begin{array}{l}3 \text { months after } \\
\text { BMCs-Tx }\end{array}$ & $\begin{array}{l}6 \text { months after } \\
\text { BMCs-Tx }\end{array}$ & $\begin{array}{l}12 \text { months after } \\
\text { BMCs-Tx }\end{array}$ \\
\hline Global EF (\%) & $46 \pm 10$ & $53 \pm 8 *$ & & $52 \pm 8 *$ \\
\hline The size of infarct area $(\%)$ & $27 \pm 9$ & $19 \pm 8 * *$ & & $18 \pm 5 * *$ \\
\hline Infarct wall movement velocity $(\mathrm{cm} / \mathrm{s})$ & $1.80 \pm 0.74$ & $2.98 \pm 0.89 * *$ & & $3.45 \pm 0.5 * *$ \\
\hline LVEDV (ml) & $138 \pm 34$ & $139 \pm 32 * * *$ & & $138 \pm 32 * * *$ \\
\hline LVESV (ml) & $75 \pm 20$ & $65 \pm 10 *$ & & $66 \pm 10 *$ \\
\hline $\mathrm{SVI}\left(\mathrm{ml} / \mathrm{m}^{2}\right)$ & $34 \pm 10$ & $42 \pm 9 *$ & & $41 \pm 8 *$ \\
\hline \multicolumn{5}{|l|}{ Migration capacity } \\
\hline Cytokine SDF-1 (\%) & $85 \pm 10$ & $127 \pm 13 * *$ & $130 \pm 20 * *$ & $129 \pm 19 * *$ \\
\hline Cytokine VEGF (\%) & $92 \pm 9$ & $134 \pm 15 * *$ & $141 \pm 22 * *$ & $142 \pm 28 * *$ \\
\hline \multicolumn{5}{|l|}{ Colony forming unit capacity (CFU) } \\
\hline Erythroid (CFU-E) & $48 \pm 5$ & $99 \pm 15^{* *}$ & $116 \pm 22 * *$ & $112 \pm 20 * *$ \\
\hline Granulocyte Makrophage (CFU-GM) & $13 \pm 3$ & $32 \pm 5 * *$ & $38 \pm 8 * *$ & $40 \pm 7 * *$ \\
\hline $\mathrm{BNP}(\mathrm{pg} / \mathrm{ml})$ & $159 \pm 73$ & $65 \pm 25 * *$ & $65 \pm 27 * *$ & $66 \pm 19 * *$ \\
\hline NYHA classification & $2.4 \pm 0.4$ & $1.69 \pm 0.6 * *$ & $1.6 \pm 0.5 * *$ & $1.6 \pm 0.6 * *$ \\
\hline
\end{tabular}

Values are mean $\pm \mathrm{SD}$. BM-CPCs, Bone marrow derived circulating progenitor cells, NYHA New York Heart Association, BNP B-type natriuretic peptide, Global EF Global ejection fraction, LVEDV End-diastolic volume, LVESV End-systolic volume, SVI Stroke volume index. There was no significant difference in baseline cardiac function, clinical function status parameters as well as functional activity of BM-CPCs between both groups at baseline. ${ }^{*} p=0.01-0.001$ (compared to baseline); ${ }^{* *} p<0.001$ (compared to baseline); ${ }^{* *} p=$ non significant (NS) 
Table 3 Cardiac function, clinical function status parameters and functional activity of BM-CPCs at baseline and 3,6 as well as 12 months after coronary angiography in control group without BMCs-Tx

\begin{tabular}{|c|c|c|c|c|}
\hline & $\begin{array}{l}\text { Immediately pre coronary } \\
\text { angiography }\end{array}$ & $\begin{array}{l}3 \text { months after coronary } \\
\text { angiography }\end{array}$ & $\begin{array}{l}6 \text { months after coronary } \\
\text { angiography }\end{array}$ & $\begin{array}{l}12 \text { months after coronary } \\
\text { angiography }\end{array}$ \\
\hline Global EF (\%) & $46 \pm 10$ & $47 \pm 7 * * *$ & & $46 \pm 9 * * *$ \\
\hline The size of infarct area $(\%)$ & $29 \pm 9$ & $28 \pm 9 * * *$ & & $26 \pm 8 * * *$ \\
\hline Infarct wall movement velocity $(\mathrm{cm} / \mathrm{s})$ & $1.86 \pm 0.96$ & $1.93 \pm 0.76^{* * *}$ & & $1.99 \pm 0.9 * * *$ \\
\hline LVEDV (ml) & $141 \pm 28$ & $142 \pm 31 * * *$ & & $140 \pm 30^{* * *}$ \\
\hline LVESV (ml) & $76 \pm 17$ & $75 \pm 15^{* * *}$ & & $76 \pm 16^{* * *}$ \\
\hline $\mathrm{SVI}\left(\mathrm{ml} / \mathrm{m}^{2}\right)$ & $36 \pm 10$ & $35 \pm 8 * * *$ & & $34 \pm 9 * * *$ \\
\hline \multicolumn{5}{|l|}{ Migration capacity } \\
\hline Cytokine SDF-1 (\%) & $88 \pm 10$ & $91 \pm 10^{* * *}$ & $90 \pm 10^{* * *}$ & $85 \pm 16^{* * *}$ \\
\hline Cytokine VEGF (\%) & $98 \pm 5$ & $102 \pm 9 * * *$ & $100 \pm 20 * * *$ & $98 \pm 15^{* * *}$ \\
\hline \multicolumn{5}{|l|}{ Colony forming unit capacity (CFU) } \\
\hline Erythroid (CFU-E) & $51 \pm 5$ & $49 \pm 10^{* * *}$ & $49 \pm 13 * * *$ & $50 \pm 15^{* * *}$ \\
\hline Granulocyte Makrophage (CFU-GM) & $12 \pm 2$ & $12 \pm 4 * * *$ & $15 \pm 8 * * *$ & $11 \pm 6 * * *$ \\
\hline $\mathrm{BNP}(\mathrm{pg} / \mathrm{ml})$ & $157 \pm 84$ & $130 \pm 80 * * *$ & $128 \pm 60 * * *$ & $141 \pm 42 * * *$ \\
\hline NYHA classification & $2.5 \pm 0.9$ & $2.45 \pm 0.9 * * *$ & $2.1 \pm 0.7 * * *$ & $2.3 \pm 0.6 * * *$ \\
\hline
\end{tabular}

Values are mean $\pm \mathrm{SD}$. BM-CPCs, Bone marrow derived circulating progenitor cells, $N Y H A$ New York Heart Association, $B N P$ B-type natriuretic peptide, Global EF Global ejection fraction, LVEDV End-diastolic volume, LVESV End-systolic volume, SVI Stroke volume index. There was no significant difference in baseline cardiac function, clinical function status parameters as well as functional activity of BM-CPCs between both groups at baseline. ${ }^{*} p=0.01-0.001$ (compared to baseline); $* *<0.001$ (compared to baseline); $* * * p=$ non significant (NS)

there was no significant change between baseline and 3, 6, 12 months after coronary angiography in control group (Fig. 2a and b, Tables 2 and 3). Likewise, there was a significant increase of colony forming capacity 3,6 , 12 months after cell therapy as compared to baseline and to control group. Interestingly, no significant difference was observed in the colony forming capacity between baseline and 3, 6, 12 months after coronary angiography in patients without cell therapy (Fig. 3a and b, Table 2 and 3).

\section{Discussion}

In this prospective randomized controlled study we could demonstrate improved functional activity of the bone marrow derived circulating progenitor cells after intra coronary autologous freshly isolated bone marrow cells transplantation in patients with IHD.

Despite improved pharmacological therapy, congestive heart failure remains the leading cause of cardiovascular mortality in industrialized world [20]. The use of stem cellbased therapy is becoming increasingly recognized as having the potential to salvage damaged myocardium and to promote endogenous repair of cardiac tissue, thus having the potential for the treatment of heart failure [21, 22]. Experimental studies demonstrated that intravascular or intramyocardial administration of BMCs or CPCs may contribute to functional regeneration of infarcted myocardium and enhance neovascularization of ischaemic myo- cardium [7-10]. Clinical pilot and randomized trials suggested, that the intracoronary infusion of autologous BMCs is safe and feasible as well as beneficially affects left ventricular contractile recovery and infarct size in patients with AMI [11-15]. Moreover, BMCs have been injected directly into the myocardium in patients with ischemic heart disease and have been shown to have a benefical effect on cardiac function [23-25]. Likewise, it was reported, that intracoronary infusion of BMCs in patients with ischemic heart disease improves left ventricular function [26, 27]. In our study, we demonstrated that the infarct size reduced, whereas the global EF and regional infarct wall movement velocity increased 3 and 12 months after intracoronary cell therapy in patients with IHD. This observation is in line with the data of Strauer et al. [26]. and Assmus et al. [27]. In addition, we observed improvement in NYHA classification as well as significant decrease of BNP level 3, 6 and 12 months after cell therapy. Cell isolation procedures are crucial for the functional activity of the administered cellular product. In our trial we chose to use a point of care system for the preparation of the treating cell composition. We demonstrated the same results for the first time with intracoronary freshly isolated BMCs-Tx by use a point of care system with Harvest BMAC-system for the preparation of the treating cell composition, not Ficoll gradient separation as in other studies. Unlike many previously conducted trials that employed Ficoll gradient separation as the method of cell collection, which produces a very limited cell linage spectrum. The cellular composi- 

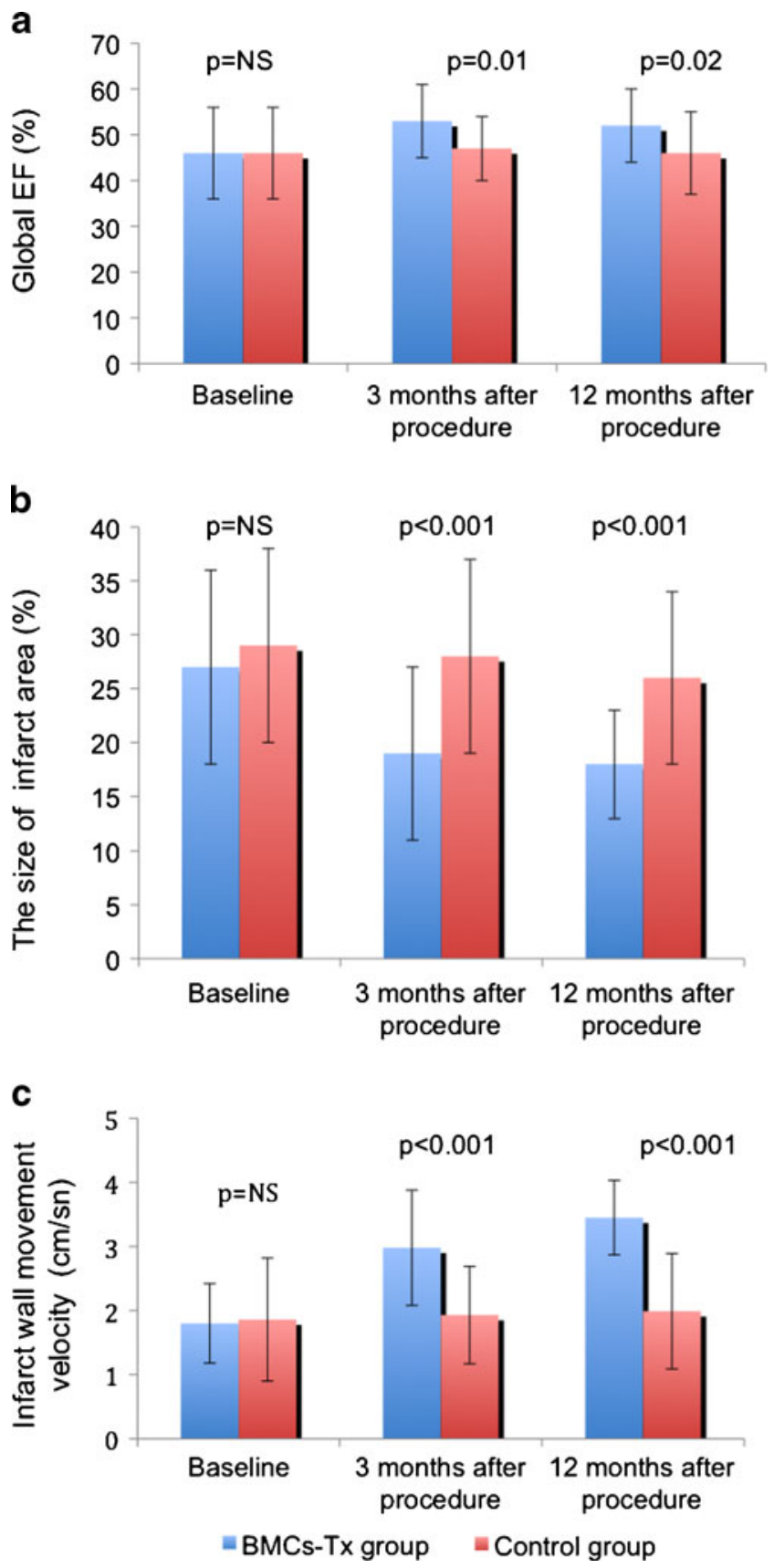

Fig. 4 a, b and c. Global EF, infarct size and the wall movement velocity of the infarcted area were measured by left ventriculography immediately pre and 3,12 months after procedure in both groups. There were no significant baseline differences in global EF, infarct size and in infarct wall movement velocity between the two groups. Global EF and infarct wall movement velocity significantly increased 3 and 12 months after cell therapy as compared to control group. Furthermore, there was a significant decrease of infarct size 3 and 12 months after cell transplantation compared to control group without cell therapy. Moreover, no significant changes were observed in the control group at follow-up

tion of the concentrate, which was prepared by use a point of care system, differs from that prepared using the Ficoll method. The Ficoll composition contains predominantly mononuclear cells (lymphocytes, erythroblasts and mono-
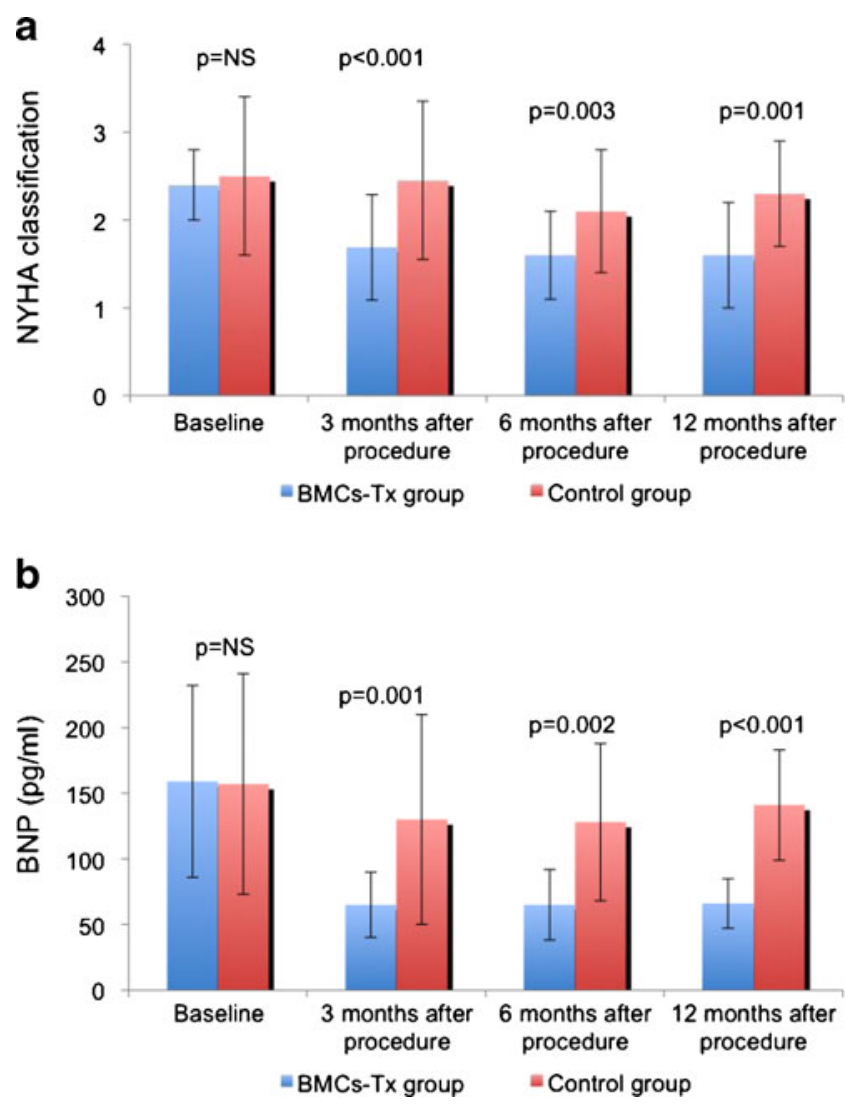

Fig. 5 a and b. NYHA classification and BNP levels in both groups. There were no significant differences of baseline NYHA classification and of BNP level between two groups. 3, 6 and 12 months after cell therapy there were a significant decrease of NYHA classification and of BNP level compared to control group without cell therapy. Moreover, no significant changes were observed in the control group at follow up

cytes) and very few granulocytes. The point of care system concentrates contain nucleated cell population with mononuclear cells and specific stem cell population $(\mathrm{CD} 34+$ and $\mathrm{CD} 133+$ ) as well as the platelets from the marrow aspirate (Table 4). Importantly, however, the point of care device provided advantage of significantly higher yield of isolated bone marrow cells compared to the Ficoll protocol. Thus, if the number of infused cells in invivo neovascularization model was adjusted for this higher yield of bone marrow cells, the treatment effect was significantly greater compared to Ficoll BMCs, as assessed by limb perfusion mesearument [28]. One obvious difference in the two compositions is the presence of significant numbers of granulocytes and platelets in the point of care system composition. Platelets and granulocytes have been shown to have a positive effect on the neovascular potential of the resulting concentrate. The presence of platelets within composition could be important because it has been shown that these platelet-derived mediators also potently enhance postnatal angiogenesis. Iba and colleagues demonstrated that implantation of mononuclear cells together with 
Table 4 The cellular composition of bone marrow aspirate and bone marrow concentrate by use of point of care system in the group with BMCsTx

Bone Marrow Aspirate (Pre Separation, 120 cc)
$25 \pm 9$

$0.21 \pm 0.07$

$0.07 \pm 0.004$

$155 \pm 19$

$98 \pm 1.5$
Bone Marrow Concentrate (Post Separation, $20 \mathrm{cc}$ )
$99 \pm 25$

$0.95 \pm 0.1$

$0.35 \pm 0.02$

$705 \pm 174$

Viability of cells $(\%)$

platelets into ischemic limbs more effectively augments collateral vessel formation by supplying various angiogenic factors, in which VEGF played a key role [29] Indeed, Massberg and colleagues provided compel ling evidence that platelets generate the critical signal that recruits CD34+ bone marrow cells and c-Kit + Sca-1+ Lin- bone marrowderived progenitor cells to sites of injury [30]. Therefore, these findings strongly support the notion that implanted platelets play a pivotal role in stem and progenitor recruitment and provide a rationale for the fact that point of care system produced functional in vivo results similar to or better than Ficoll. In our study despite higher number of platelets we observed no immediate periprocedure as well as post procedure adverse complications. In addition, unlike Ficoll isolation where cells are resuspended in a serum free medium, point of care system is always resuspended in the patient's own plasma. Thus, the isolated cells are not removed from their natural plasma microenvironment, which may be help to sustain the functionality of the cells. This has been further supported by experimental study of Hermann et al., who showed that the point of care system composition to be significantly more bioactive than the Ficoll composition. Intriguingly, however, due to the greater yield of cells generated by use a point of care system, the cellular product isolated from a given bone marrow aspirate by use a point of care device may actually translate into even greater therapeutic effects. Additionally, practical aspects may also deserve consideration. Importantly, a major limitation of the Ficoll isolation procedure for clinical applications is that it is strongly investigator dependant, immensely time consuming and requires a good manufacturing practice (GMP) facility. In this study we were able to demonstrate that such complex methods are not necessary to achieve established results. As the concentration process by use of point of care system, everything can be accomplished in one session without adding excessive time to the overall procedure circumventing the previously mentioned disadvantages of the Ficoll isolation process. The point of care device provides a much shorter turnaround time. Therefore, this device represents a cost-effective and time-efficient stand-alone technique for the isolation of autologous bone marrow cells suitable for cell therapy regimens in the rapidly growing field of regenerative medicine.

Several hypotheses have been proposed about, how intracoronary cell therapy improves myocardial function. I) Experimental studies addressing the capacity of transplanted bone marrow-derived stem cells to differentiate into the cardiomyogenic lineage yielded conflicting results. Recent well-conducted studies suggest that the BMCs do not transdifferentiate into cardiomyocytes but adopt mature hematopoietic characteristics. In contrast to embryonic stem cells, most adult stem or progenitor cells do not spontaneously differentiate into cardiomyocytes but rather require an adequate stimulus to do so. II) Another proposed mechanism is that cell therapy may increase angiogenesis and improve blood supply to ischemic regions, potentially aiding in the revascularization of hibernating myocardium and inhibiting cardiomyocyte apoptosis. Additionally or alternatively, the local microenvironment plays an important role to induce cell fate changes by physical cell-to-cell interaction or by providing paracrine factors promoting tissue repair [31, 32].

Cell-based therapy is a promising option for treatment of ischemic disease. However, cell therapy is in its early stages, and various questions remain. BMCs are best characterized and have been used in the majority of clinical trials performed to date. BMCs contains a complex assortment of progenitor cells, including hematopoietic stem cells (HSCs), mesenchymal stem cells (MSCs) or stromal cells and multipotential adult progenitor cells (MAPCs) [33]. BM-CPCs is another population of progenitor cells that has also been shown to have therapeutic potential in the pool of progenitor cells circulating within the blood. BM-CPCs are capable of proliferating and differentiating into endothelial cells and are therefore candidates for vascular regeneration [34-36]. Experimental and clinical studies suggest that the systemic application or mobilization of stem cells and progenitor cells beneficially influences the repair of endothelial cells after injury and the progression of atherosclerosis [37-41]. Previous studies demonstrate that risk factors for coronary artery disease correlate with number and functional activity of BM-CPCs [17]. Not only is the quantity of BM-CPCs altered, but their 
function is also modified by ischemic conditions and therapeutic interventions [19]. Migration is essential for the stem/progenitor cells to invade the ischemic tissue. SDF-1 and VEGF are both profoundly upregulated in hypoxic tissue $[42,43]$ and thus represent physiologically relevant chemoattractants for the recruitment of circulating progenitor cells to sites of ischemia. Indeed, intramuscular injection of the chemoattractant chemokine SDF-1 has recently been shown to increase the number of incorporated BM-CPCs and to improve neovascularization in vivo [44]. Thus, the migratory response toward SDF-1 may indeed play a crucial role for integration of BM-CPCs in ischemic tissue. In addition, the accumulation of cardiovascular risk factors or an increased overall risk is associated with impaired colony forming activity of CPCs in healthy men [16]. We found significant increase of migratory activity and colony forming activity after cell therapy in contrast to control group without cell therapy. The occurrence of a first major cardiovascular event (acute myocardial infarction, hospitalization, revascularization or death from cardiovascular causes) was associated with reduced BM-CPCs levels and functional activity in patients with coronary artery disease [45]. Moreover, intra coronary administration of BMCs is associated with a significant reduction of major adverse cardiovascular events after AMI [46]. Previous studies demonstrate that patients with heart failure (HF) show endothelial dysfunction and in HF, nitric oxide production is diminished, whereas rate of endothelial apoptosis is increased [47, 48]. Moreover, the impaired neovascularisation in mice lacking eNOS is related to defect in progenitor cell mobilization from bone marrow [49]. Mechanistically, the improved perfusion capacity, which was demonstrated in the pilot TOPECARE- and REPAIRAMI trial in patients after cell therapy, may increase epicardial artery shear stress and stimulate the endothelium to release NO, which may enhance the functional activity of BM-CPCs and exerts antiatherosclerotic functions [50, 51]. Additionally, The presence of immature circulating cells in the peripheral blood has been advocated as a marker of an organism's regenerative capacity [52].

The primary limitation of this study is the lack of placebo arm and the measurement of cardiac imaging. Moreover, for better understanding we added left ventricular volume data in our study, which was also investigated in several trials [11, 12 , 15, 26, 27]. Therefore, a placebo-controlled study will be needed to validate the hypothesis.

In the present study we could demonstrate that intracoronary transplantation of autologous freshly isolated BMCs improved global EF and reduced infarct size significantly in patients with IHD after 3 and 12 months. Moreover, we observed a significant improvement of BM-CPCs functional activity even 3, 6 and 12 months after cell transplantation. This interesting observation could be implemented in future large-scale randomized studies, where the BM-CPCs functional activity after transplantation may serve as predictor for identifying IHD patients with greater benefit after cell therapy.

Disclosures The authors indicate no potential conflicts of interest.

Open Access This article is distributed under the terms of the Creative Commons Attribution Noncommercial License which permits any noncommercial use, distribution, and reproduction in any medium, provided the original author(s) and source are credited.

\section{References}

1. Luttun, A., Carmeliet, G., \& Carmeliet, P. (2002). Vascular progenitors: from biology to treatment. Trends in Cardiovascular Medicine, 12, 88-96.

2. Szmitko, P. E., Fedak, P. W., Weisel, R. D., Stewart, D. J., Kutryk, M. J., \& Verma, S. (2003). Endothelial progenitor cells, new hope for a broken heart. Circulation, 107, 3093-3100.

3. Reed, M. J., Karres, N., Eyman, D., \& Edelberg, J. (2007). Endothelial precursor cells. Stem Cell Reviews, 3, 218-225.

4. Asahara, T., Murohara, T., Sullivan, A., et al. (1997). Isolation of putative progenitor endothelial cells for angiogenesis. Science, 275, 964-967.

5. Rafii, S., \& Lyden, D. (2003). Therapeutic stem and progenitor cell transplantation for organ vascularization and regeneration. Natural Medicines, 9, 702-712.

6. Perin, E. C., Geng, Y. J., \& Willerson, J. T. (2003). Adult stem cell therapy in perspective. Circulation, 107, 935-938.

7. Orlic, D., Kajstura, J., Chimenti, S., et al. (2001). Mobilised bone marrow cells repair the infarcted heart, improving function and survival. Proceedings of the National Academy of Sciences of the United States of America, 98, 10344-10349.

8. Orlic, D., Kajstura, J., Chimenti, S., et al. (2001). Bone marrow cells regenerate infarcted myocardium. Nature, 410, 701-705.

9. Kocher, A. A., Schuster, M. D., Szabolcs, M. J., et al. (2001). Neovascularization of ischaemic myocardium by human bonemarrow-derived angioblasts prevents cardiomyocyte apoptosis, reduces remodeling and improves cardiac function. Natural Medicines, 7, 430-436.

10. Fuchs, S., Baffour, R., Zhou, Y. F., et al. (2001). Transendocardial delivery of autologous bone marrow enhances collateral perfusion and regional function in pigs with chronic experimental myocardial ischaemia. Journal of the American College of Cardiology, 37, 1726-1732.

11. Assmus, B., Schachinger, V., Teupe, C., et al. (2002). Transplantation of progenitor cells and regeneration enhancement in acute myocardial infarction (TOPCARE-AMI). Circulation, 106, 3009-3017.

12. Strauer, B. E., Brehm, M., Zeus, T., et al. (2002). Repair of infarcted myocardium by autologous intracoronary mononuclear bone marrow cell transplantation in humans. Circulation, 106, 1913-1918.

13. Wollert, K. C., Meyer, G. P., Lotz, J., et al. (2004). Intracoronary autologous bone-marrow cell transfer after myocardial infarction: the BOOST randomised controlled clinical trial. Lancet, 364, 141-148.

14. Janssens, S., Dubois, C., Bogaert, J., et al. (2006). Autologous bone marrow-derived stem-cell transfer in patients with STsegment elevation myocardial infarction: double-blind, randomised controlled trial. Lancet, 367, 113-121. 
15. Schachinger, V., Erbs, S., Elsasser, A., et al. (2006). Inracoronary bone marrow-derived progenitor cells in acute myocardial infarction. The New England Journal of Medicine, 355, 1210-1221.

16. Hill, J. M., Zalos, G., Halcox, J. P., et al. (2003). Circulating endothelial progenitor cells, vascular function, and cardiovascular risk. The New England Journal of Medicine, 348, 593-600.

17. Vasa, M., Fichtlscherer, S., Aicher, A., et al. (2001). Number and migratory activity of circulating endothelial progenitor cells inversely correlate with risk factors for coronary artery disease. Circulation Research, 89, E1-E7.

18. Sheehan, F. H., Bolson, E. L., Dodge, H. T., Mathey, D. G., Schofer, J., \& Woo, H. W. (1986). Advantages and applications of the centreline method for characterizing regional ventricular function. Circulation, 74, 293-305.

19. Heeschen, C., Lehman, R., Honold, J., et al. (2004). Profoundly reduced neovascularization capacity of bone marrow mononuclear cells derived from patients with chronic ischemic heart disease. Circulation, 109, 1615-1622.

20. Towbin, J. A., \& Bowles, N. E. (2002). The failing heart. Nature, 415, 227-233.

21. Mayorga, M., Finan, A., \& Penn, M. (2009). Pre-transplantation specification of stem cells to cardiac lineage for regeneration of cardiac tissue. Stem Cell Reviews, 5, 51-60.

22. Vieyra, D. S., Jackson, K. A., \& Goodell, M. A. (2005). Plasticity and tissue regenerative potential of bone marrow-derived cells. Stem Cell Reviews, 1, 65-69.

23. Tse, H. F., Chan, K. J. Y., Lo, G., et al. (2003). Angiogenesis in ischaemic myocardium by intramyocardial autologous bone marrow mononuclear transplantation. Lancet, 361, 47-49.

24. Stamm, C., Westphal, B., Kleine, H., et al. (2003). Autologous bone-marrow stem-cell transplantation for myocardial regeneration. Lancet, 361, 45-46.

25. Akar, R. A., Durdu, S., Arat, M., et al. (2009). Five-year followup after transepicardial implantation of autologous bone marrow mononuclear cells to ungraftable coronary territories for patients with ischaemic cardiomyopathy. European Journal of Cardiothoracic Surgery, 36, 633-643.

26. Strauer, B. E., Brehm, M., Zeus, T., et al. (2005). Regeneration of human infarcted heart muscle by intracoronary autologous bone marrow cell transplantation in chronic coronary artery disease (The IACT Study). Journal of the American College of Cardiology, 46, $1651-1658$.

27. Assmus, B., Honold, J., Schachinger, V., et al. (2006). Transcoronary transplantation of progenitor cells after myocardial infarction. The New England Journal of Medicine, 355, 1222-1232.

28. Hermann, P. C., Huber, S. L., Herrler, T., et al. (2008). Concentration of bone marrow total nucleated cells by a pointof-care device provides a high yield and preserves their functional activity. Cell Transplantation, 16(10), 1059-1069.

29. Iba, O., Matsubara, H., Nozawa, Y., et al. (2002). Angiogenesis by implantation of peripheral blood mononuclear cells and platelets into ischemic limbs. Circulation, 106, 2019-2025.

30. Massberg, S., Konrad, I., Schürzinger, K., et al. (2006). Platelets secrete stromal cell-derived factor 1 alpha and recruit bone marrow-derived progenitor cells to arterial thrombi in vivo. The Journal of Experimental Medicine, 203, 1221-1233.

31. Dimmeler, S., Burchfield, J., \& Zeiher, A. M. (2008). Cell-based therapy of myocardial infarction. Arteriosclerosis, Thrombosis, and Vascular Biology, 28, 208-216.

32. Lipinski, M. J., Biondi-Zoccai, G. G. L., Abbate, A., et al. (2007). Impact of intracoronary cell therapy on left ventricular function in the setting of acute myocardial infarction. Journal of the American College of Cardiology, 50, 1761-1767.

33. Jiang, Y., Jahagirdar, B. N., Reinhardt, R. L., et al. (2002). Pluripotency of mesenchymal stem cells derived from adult marrow. Nature, 418, 41-49.
34. Cai, X., Lin, Y., Friedrich, C. C., et al. (2009). Bone marrow derived pluripotent cells are pericytes which contribute to vascularization. Stem Cell Reviews, 5, 437-445.

35. Gehling, U. M., Ergun, S., Schumacher, U., et al. (2000). In vitro differentiation of endothelial cells from AC133-positive progenitor cells. Blood, 95, 3106-3112.

36. Gunsilius, E., Duba, H. C., Petzer, A. L., Kähler, C. M., \& Gasti, G. A. (2001). Contribution of endothelial cells of hematopoietic origin to blood vessel formation. Circulation Research, 88(1)-E1.

37. Kong, D., Melo, L. G., Gnecchi, M., et al. (2004). Cytokineinduced mobilization of circulating endothelial progenitor cells enhances repair of injured arteries. Circulation, 110, 2039-2046.

38. Nowak, G., Karrar, A., Holmen, C., et al. (2004). Expression of vascular endothelial growth factor receptor-2 or tie-2 on peripheral blood cells defines functionally competent cell populations capable of reendothelialization. Circulation, 110, 3699-3707.

39. Strehlow, K., Werner, N., Berweiler, J., et al. (2003). Estrogen increases bone marrow-derived endothelial progenitor cell production and diminishes neointima formation. Circulation, 107, 3059-3065.

40. Walter, D. H., Rittig, K., Bahlmann, F. H., et al. (2002). Statin therapy accelerates reendothelialization: a novel effect involving mobilization and incorporation of bone marrow-derived endothelial progenitor cells. Circulation, 105, 3017-3024.

41. Werner, N., Priller, J., Laufs, U., et al. (2002). Bone marrowderived progenitor cells modulate vascular reendothelialization and neointimal formation: effect of 3-hydroxy-3-methylglutaryl coenzyme A reductase inhibition. Arteriosclerosis, Thrombosis, and Vascular Biology, 22, 1567-1572.

42. Lee, S. H., Wolf, P. L., Escudero, R., et al. (2000). Early expression of angiogenesis factors in acute myocardial ischemia and infarction. N Eng J Med, 342, 626-633.

43. Pilarisetti, K., \& Gupta, S. K. (2001). Cloning and relative expression analysis of rat stromal cell derived factor-1 (SDF-1) 1: SDF-1 alpha mRNA is selectively induced in rat model of myocardial infarction. Inflammation, 25, 293-300.

44. Yamaguchi, J., Kussano, K. F., Masuo, O., et al. (2003). Stromal cell-derived factor-1 effects on ex vivo expanded endothelial progenitor cell recruitment for ischemic neovascularization. Circulation, 107, 1322-1328.

45. Werner, N., Kosiol, S., Schiegl, T., et al. (2005). Circulating endothelial progenitor cells and cardiovascular outcomes. The New England Journal of Medicine, 353, 999-1007.

46. Schächinger, V., Erbs, S., Elsässer, A., et al. (2006). Improved clinical outcome after intracoronary administration of bone-marrow-derived progenitor cells in acute myocardial infarction: final 1-year results of the REPAIR-AMI trial. European Heart Journal, 27, 2775-2783.

47. Katz, S. D., Khan, T., Zeballos, G. A., et al. (1999). Decreased activity of the L-arginine-nitric-oxide metabolic pathway in patients with congestive heart failure. Circulation, 99, 2113-2117.

48. Agnoletti, L., Curello, S., Bachetti, T., et al. (1999). Serum from patients with severe heart failure down regulates eNOS and is proapoptotic: role of tumor necrosis factor-alpha. Circulation, 100, 1983-1991.

49. Aicher, A., Heeschen, C., Mildner-Rihm, C., et al. (2003). Essential role of endothelial nitric oxide synthase for mobilization of stem and progenitor cells. Natural Medicines, 9, 1370-1376.

50. Coke, J. P., Singer, A. H., Tsao, P., Zera, P., Rowan, R. A., \& Billingham, M. E. (1992). Antiatherogenic effects of L-arginine in the hypercholesterolemic rabbit. Journal of Clinical Investigation, 90, 1168-1172.

51. Candipan, R. C., Wang, B. Y., Bultrago, R., Tsao, P. S., \& Cooke, J. P. (1996). Regression or progression. dependency on vascular nitric oxide. Arteriosclerosis, Thrombosis, and Vascular Biology, $16,44-50$.

52. Blau, H. M., Brazelton, T. R., \& Weimann, J. M. (2001). The evolving concept of a stem cell: entity or function? Cell, 105, 829-841. 